\title{
Diversity in electrochemical oxidation of dihydroxybenzenes in the presence of 1-methylindole
}

\author{
DAVOOD NEMATOLLAHI ${ }^{\mathrm{a}, *}$ and VAHID HEDAYATFAR ${ }^{\mathrm{b}}$ \\ ${ }^{a}$ Faculty of Chemistry, Bu-Ali Sina University, 65178-38683, Hamedan, Iran \\ ${ }^{\mathrm{b}}$ Chemistry Department, Faculty of Science, Islamic Azad University, Arak Branch, \\ P.O.Box 38135-567, Arak, Iran \\ e-mail: nemat@basu.ac.ir
}

MS received 25 September 2010; revised 11 February 2011; accepted 9 July 2011

\begin{abstract}
Electrochemical oxidation of some catechol derivatives (1a-e) have been studied in water/ acetonitrile solution containing 1-methylindole (3) as a nucleophile, using cyclic voltammetry and controlledpotential coulometry. An interesting diversity in the mechanisms has been observed in electrochemical oxidation of catechol derivatives (1a-e) in the presence of $\mathbf{3}$. In this work, we have proposed reaction schemes $E C E C, E C E C E$ and ECECECE for oxidation of 1a-e in the presence of $\mathbf{3}$.
\end{abstract}

Keywords. 1-Methylindole; catechol; Michael addition reaction; cyclic voltammetry; electrochemical oxidation.

\section{Introduction}

Indole is a powerful antioxidant and it appears to be especially effective against breast and cervical cancer because of its ability to increase the breakdown of estrogen in the human body. ${ }^{1,2}$ Also, the indole structure can be found in many organic compounds like the amino acid tryptophan and in tryptophan-containing protein, in pigments, and in alkaloids. ${ }^{1,2}$ In addition, many pharmaceutical drugs are included of specifically substituted indoles. ${ }^{1,2}$ On the other hand, catechol derivatives play an important role in mammalian metabolism. Many compounds of this type are known to be secondary metabolites of higher plants. ${ }^{3}$ Catechol itself and monosubstituted catechols are active in part against Pseudomonas and Bacillus species. ${ }^{4}$ It was thought that synthesis of compounds with both structures of catechols and indoles would be useful from the point of view of pharmaceutical properties. In this direction, we have recently synthesized some derivatives of 4( $1 \mathrm{H}$-indol-3-yl)benzene-1,2-diol using electrochemical oxidation of catechols in the presence of indole as nucleophile in acetate buffer $(\mathrm{pH}=5.0)$ via $E C$ mechanism. ${ }^{5}$ In continuation of interest in compounds containing catechol and indole, in this work, we study elec-

${ }^{*}$ For correspondence trochemical oxidation of catechols in the presence of 1 -methylindole in water/acetonitrile $(50 / 50, \mathrm{v} / \mathrm{v}) \mathrm{mix}-$ ture and proposed a reaction mechanism (ECEC) and final products (figure 1, compound $\mathbf{I}$ ) for it.

Furthermore, our literature survey shows that compounds with both structures of benzoquinones and indoles have pharmaceutical properties. In this direction, it is recognized that, the 3 -indolylbenzoquinone fragment is a core structure in a number of biologically active natural products such as asterriquinones. ${ }^{6,7}$ The asterriquinones (figure 1, compound II) and demethylasterriquinones (figure 1, compound III) exhibit a wide spectrum of biological activities including antitumor properties and are inhibitors of HIV reverse transcriptase. ${ }^{8-10}$ The importance of these compounds has motivated us and many workers to synthesize a number of indolylquinone and numerous methods have been developed for their preparation. ${ }^{11-19}$ Following our experience in electrochemical oxidation of catechols in the presence of nucleophiles ${ }^{20}$ we envisaged that the attachment of two indoles group to an $o$-quinone ring might cause an enhancement of pharmaceutical properties and medicinal activities. This idea prompted us to investigate the electrochemical oxidation of 2,3-dihydroxybenzoic acid and 3,4-dihydroxybenzoic acid in the presence of 1-methylindole and we have proposed reaction mechanisms ECECE and ECE$C E C E$ and final products $\mathbf{I V}$ and $\mathbf{V}$, respectively (figure 1). 


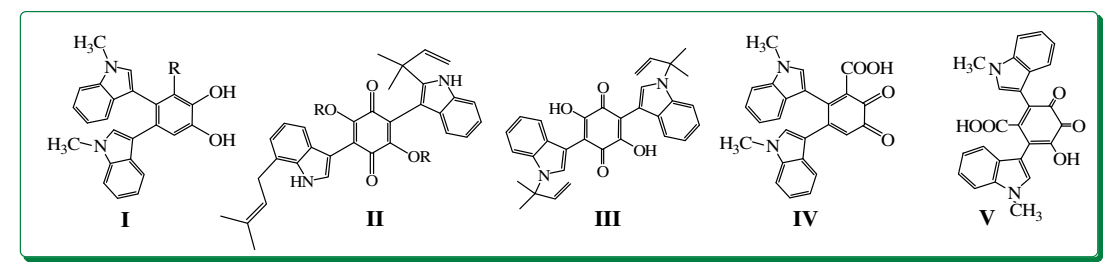

Figure 1. The structure of compounds reported here (I, IV and V), asterriquinone (II) and demethylasterriquinone (III).

\section{Experimental}

\subsection{General}

Cyclic voltammetry, controlled-potential coulometry and preparative electrolysis were performed using an Autolab model PGSTAT 20 potentiostat/galvanostat. The working electrode used in voltammetry experiment was a glassy carbon disc ( $1.8 \mathrm{~mm}$ diameter) which was polished sequentially with alumina powder and a platinum wire was used as counter electrode. The working electrode used in controlled-potential coulometry and macroscale electrolysis was an assembly of four carbon rods $(6 \mathrm{~mm}$ diameter and $4 \mathrm{~cm}$ length) and a large stainless steele plate constitute the counter electrode (for more details, see ref. ${ }^{5}$ ). For activation of carbon electrodes, the electrolysis was interrupted during the electrolysis and the carbon anode was washed in acetone. The working electrode potentials were measured versus SCE (all electrodes from AZAR Electrode). All catechols were reagent-grade materials from Aldrich and phosphate salts were of pro-analysis grade from E. Merck. These chemicals were used without further purification. All experiment was carried out at a temperature of $25 \pm 1^{\circ} \mathrm{C}$. Melting points of all synthesized compounds were determined in open capillary tubes and are uncorrected. IR spectra $(\mathrm{KBr})$ were recorded on IFS66 Bruker FT-IR spectrometer. ${ }^{1} \mathrm{H}$ NMR spectra (DMSO- $d 6$ ) were recorded on BRUKER DRX-400 AVANCE spectrometer operating at $400 \mathrm{MHz}$, respectively Mass spectra were recorded on a QP-1100EX Shimadzu Mass spectrometer operating at an ionization potential of $70 \mathrm{eV}$. Because of insolubility of the 1-methylindole (3) in water, a water/acetonitrile (50:50 $\mathrm{v} / \mathrm{v})$ mixture was used. This percentage of acetonitrile $(50 \%)$ is minimum amount for dissolution of 1methylindole (3) in mixture.

\subsection{General procedure for the synthesis of $\boldsymbol{6 a}-\boldsymbol{c}, 7 \boldsymbol{d}$ and $9 e$}

A solution of phosphate buffer (ca. $80 \mathrm{ml} ; c_{\mathrm{H}^{2} \mathrm{PO}^{-}}=$ $0.188 \mathrm{M}$ and $c=c_{\mathrm{HPO}^{2-}}=0.012 \mathrm{M}, \mathrm{pH}=6.0$ ) in water/acetonitrile $(50: 50 ; 80 \mathrm{~mL})$ solution containing catechol (1a-e; $1 \mathrm{mmol})$ and 1-methylindole (3) ( $2 \mathrm{mmol})$ was electrolyzed in a two-compartment cell separated by a sintered glass membrane, at $0.35 \mathrm{~V}$ vs. SCE in the case of $1 \mathbf{a}-\mathbf{c}$ and $0.40 \mathrm{~V}$ in the case of $\mathbf{1 d}$ and 1e. The electrolysis was terminated when the current decreased by more than $95 \%$. The process was interrupted during the electrolysis and the carbon anode was washed in acetone in order to reactivate it. After electrolysis, the precipitated solid was collected by filtration and was washed several times with water. After washing, products were characterized by: IR, ${ }^{1} \mathrm{H}$ NMR and MS. The isolated yields of $\mathbf{6 a}-\mathbf{c}, 7 \mathbf{d}$ and $9 \mathbf{e}$ obtained after washing are $41,45,43,46$ and $41 \%$, respectively.

2.2a 4,5-Bis(1-methyl-1H-indol-3-yl)benzene-1,2diol (6a): m.p.: $>300^{\circ} \mathrm{C}$ (dec.). ${ }^{1} \mathrm{H}$ NMR (DMSO- $d_{6}$, $400 \mathrm{MHz}) \delta: 3.78(\mathrm{~s}, 6 \mathrm{H}$, methyl), $6.42(\mathrm{~s}, 2 \mathrm{H}$, aromatic in five-ring cycle), $7.02-7.56(\mathrm{~m}, 10 \mathrm{H}$, aromatic) 9 (broad, OH). IR $\left(\mathrm{KBr} / \mathrm{cm}^{-1}\right)$ : 3441, 1576, 1469, 1417, 1384, 1129, 741. MS $(\mathrm{m} / \mathrm{z})(\%): 368\left(\mathrm{M}^{+}\right)$, for more detail see Supporting Information.

2.2b 3-Methyl-4,5-bis(1-methyl-1H-indol-3-yl)benzene1,2-diol ( $6 \boldsymbol{b})$ : m.p.: $>300^{\circ} \mathrm{C}$ (dec.). ${ }^{1} \mathrm{H}$ NMR (DMSO$\left.d_{6}, 400 \mathrm{MHz}\right) \delta: 2.1(\mathrm{~s}, 3 \mathrm{H}$, methyl), 3.70, $3.78(\mathrm{~s}, \mathrm{~s}$ $6 \mathrm{H}$, methyl), 6.33 (s, $1 \mathrm{H}$, aromatic in five-ring cycle), 6.88-7.61 (m, 10H, aromatic), 9 (broad, OH). IR $\left(\mathrm{KBr} / \mathrm{cm}^{-1}\right): 3414,1714,1612,1473,1373,1250$, 1084, 743. MS $(\mathrm{m} / \mathrm{z})(\%) 382(2.2)\left[\mathrm{M}^{+\cdot}\right], 280(16.8)$, 253 (25.2), 131 (100).

2.2c 3-Methoxy-4,5-bis(1-methyl-1H-indol-3-yl)benzene1,2-diol (6c): m.p.: $>245^{\circ} \mathrm{C}$ (dec.). ${ }^{1} \mathrm{H}$ NMR (DMSO$\left.d_{6}, 400 \mathrm{MHz}\right) \delta: 3.51$ (s, 3H, methyl), $3.59(\mathrm{~s}, 3 \mathrm{H}$, methyl), 3.70 (s, 3H, methyl), 6.40-7.70 (m, 11H, aromatic), 8.2 (broad, OH). IR $\left(\mathrm{KBr} / \mathrm{cm}^{-1}\right): 3210,3035$, 2942, 1614, 1544, 1464, 1373, 1324, 1220, 1090, 743. MS $(\mathrm{m} / \mathrm{z})(\%): 398(8.9)\left[\mathbf{M}^{+} \cdot\right], 380(100), 269$ (100), 226 (58.8), 190 (27.3), 130 (65.1). 
2.2d 2,3-Bis(1-methyl-1H-indol-3-yl)-5,6-dioxocyclohexa1,3-dienecarboxylic acid (7d): m.p.: $>300^{\circ} \mathrm{C}$ (dec.). ${ }^{1} \mathrm{H}$ NMR (DMSO- $\left.d_{6}, 400 \mathrm{MHz}\right) \delta: 3.49$ (s, $3 \mathrm{H}$, methyl), 3.57 (s, 3H, methyl), 6.4-7.8 (m, 11H, aromatic). IR $\left(\mathrm{KBr} / \mathrm{cm}^{-1}\right): 3464,2925,1561,1411,1384,740 . \mathrm{MS}$ $(\mathrm{m} / \mathrm{z})(\%): 410\left[\mathrm{M}^{+\cdot}\right]$, for more detail see Supporting Information.

2.2e 5-Hydroxy-2,6-bis(1-methyl-1H-indol-3-yl)-3,4dioxocyclohexa-1,5-dienecarboxylic acid (9e): m.p.: $>300^{\circ} \mathrm{C}$ (dec.). IR $\left(\mathrm{KBr} / \mathrm{cm}^{-1}\right): 3434,1720,1610$, $1469,1371,744$. MS $(\mathrm{m} / \mathrm{z})(\%): 426\left[\mathrm{M}^{+\cdot}\right]$, for more detail see Supporting Information.

\section{Results and discussion}

\subsection{Electrochemical oxidation of 3-substituted catechols in the presence of 1-methylindole}

Figure 2, curve a, shows the voltammetric curve obtained for the oxidation of catechol (1a) $(1 \mathrm{mM})$ in water (containing phosphate buffer, $c_{\mathrm{H}_{2} \mathrm{PO}^{-}}=$

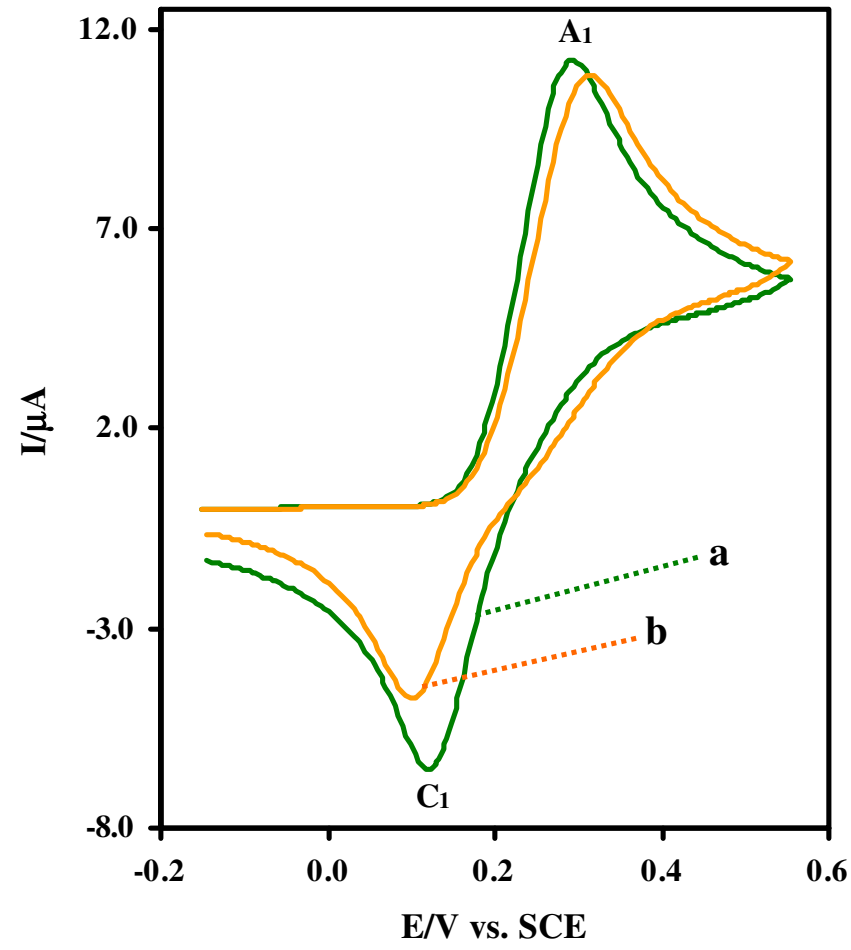

Figure 2. Cyclic voltammograms of $1 \mathrm{mM}$ catechol (1a): (a) in the absence, (b) in the presence of $20 \mathrm{mM}$ of 1methylindole (3) in water (containing phosphate buffer, $c=$ $0.2 \mathrm{M}, \mathrm{pH}=6.0) /$ acetonitrile $(50: 50 \mathrm{v} / \mathrm{v})$ mixture at glassy carbon electrode. Scan rate: $25 \mathrm{mV} \mathrm{s}^{-1} ; \mathrm{t}=25 \pm 1^{\circ} \mathrm{C}$.
$0.188 \mathrm{M}$ and $\left.c_{\mathrm{HPO}^{2-}}=0.012 \mathrm{M}, \mathrm{pH}=6.0\right) /$ acetonitrile $(50: 50 \mathrm{v} / \mathrm{v})$ mixture at a glassy carbon electrode. This percent of acetonitrile is minimum amount for dissolution of 1-methylindole (3) in water/acetonitrile mixture. In the studied potential range, a well-defined voltammetric curve is obtained that has an anodic $\left(\mathrm{A}_{1}\right)$ and the corresponding cathodic $\left(\mathrm{C}_{1}\right)$ peaks. These peaks correspond to the oxidation of catechol (1a)
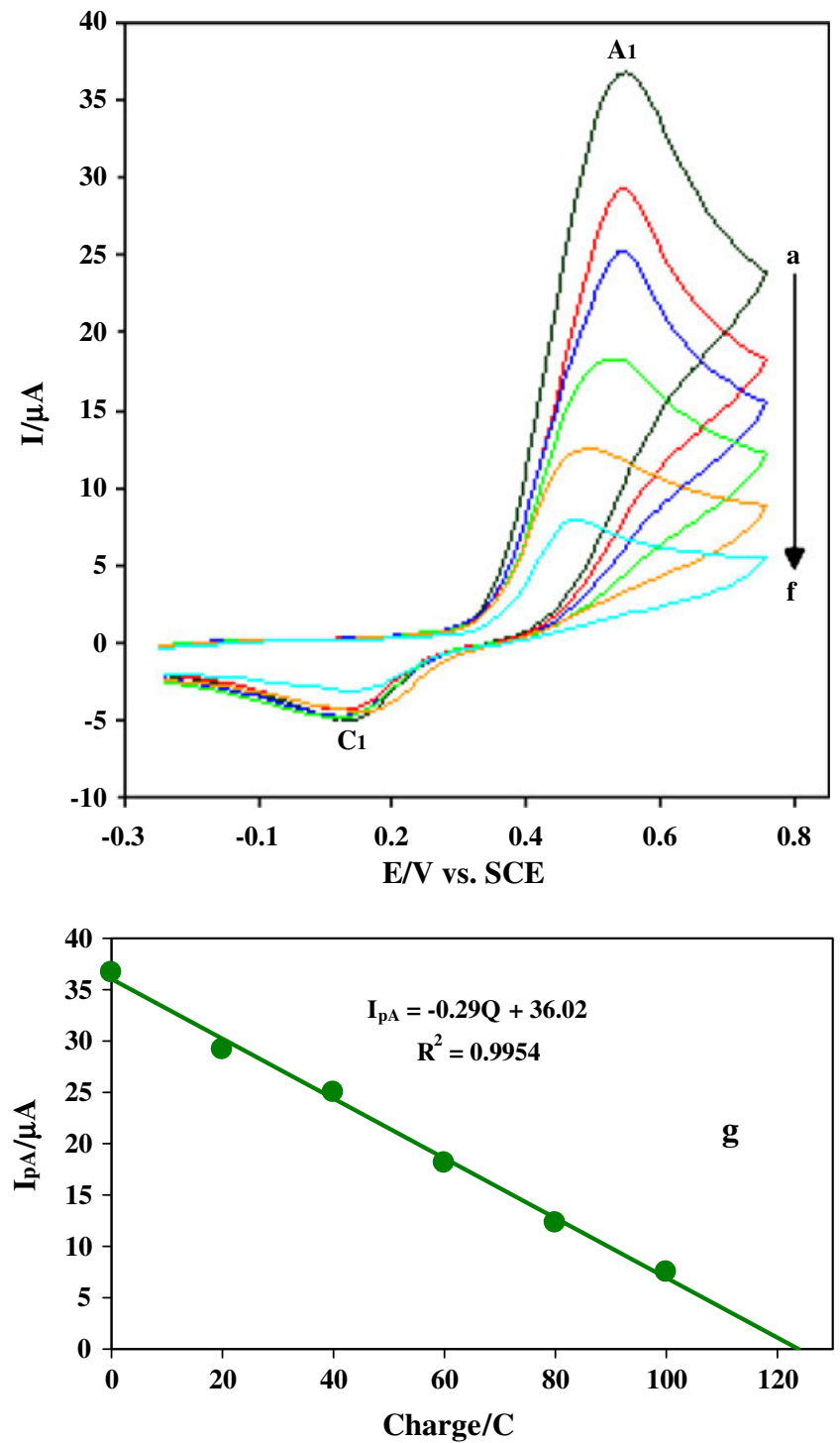

Figure 3. Cyclic voltammograms of $0.30 \mathrm{mmol}$ catechol (1a) in the presence of $0.60 \mathrm{mmol} 1$-methylindole $(3)$, in water (phosphate buffer, $c=0.2 \mathrm{M}, \mathrm{pH}=6.0$ )/acetonitrile $(50: 50 \mathrm{v} / \mathrm{v})$ mixture during controlled-potential coulometry at $0.35 \mathrm{~V}$ vs. SCE after the consumption of (a) 0, (b) 20, (c) 40, (d) 60, (e) 80 and (f) 100 C. (g) Variation of peak current $\left(I_{\mathrm{pA} 1}\right)$ vs. charge consumed. Scan rate: $100 \mathrm{mV} \mathrm{s}^{-1}$. Other conditions are the same as reported in figure 2. 
to $o$-benzoquinone 2a and vice versa within a twoelectron process. ${ }^{20}$ The oxidation of catechol (1a) in the presence of 1-methylindole (3) as a nucleophile was studied in some detail. In figure 2 , curve b shows the cyclic voltammogram obtained for a $1 \mathrm{mM}$ solution of $\mathbf{1 a}$ in the presence of $1 \mathrm{mM}$ of 1-methylindole (3). Under these conditions, the voltammogram exhibits anodic and cathodic peaks $A_{1}$ and $C_{1}$, respectively. The comparison of peak $C_{1}$ in the absence and presence of 3 shows a decrease in peak $C_{1}$ current. The existence of a subsequent chemical reaction between $o$-benzoquinone 2a and 1-methylindole (3) is supported by the following evidence: (i) Decreasing of $I_{\mathrm{pC} 1}$ during the reverse scan (figure 2), this could be indicative of the fact that electrochemically generated $o$-benzoquinone $\mathbf{2 a}$ is removed partially by chemical reaction with 1-methylindole (3). (ii) Dependency of peak current ratio $\left(I_{\mathrm{p}}^{\mathrm{Cl}} / I_{\mathrm{p}}^{\mathrm{A} 1}\right)$ on potential sweep rate. In this case, for the highest sweep rate employed a well-defined cathodic peak $\mathrm{C}_{1}$ is observed. For lower sweep rates, the peak current ratio $\left(I_{\mathrm{p}}^{\mathrm{Cl}} / I_{\mathrm{p}}^{\mathrm{Al}}\right)$ is less than one and increases with increasing sweep rate. This is indicative of departure from intermediate and arrival to diffusion region with increasing sweep rate. ${ }^{21}$ (iii) Dependency of peak current ratio $\left(I_{\mathrm{p}}^{\mathrm{Cl}} / I_{\mathrm{p}}^{\mathrm{A} 1}\right)$ on concentration of 1-methylindole (3). This is related to the increase of the homogeneous reaction rate of following chemical reaction between $o$-benzoquinone $\mathbf{2 a}$ and 1-methylindole (3) with increasing of concentration of 1-methylindole (3).

The observed shift of the $\mathrm{A}_{1}$ peak potential $\left(E_{\mathrm{pA} 1}\right)$ in curve $b$, relative to curve $a$, is due to the formation of a thin film of product at the surface of the electrode, inhibiting to a certain extent the performance of the electrode process. ${ }^{22}$

Our previous works illustrate that in acidic and neutral media, cyclic voltammograms of catechol (1a) shows one anodic and a corresponding cathodic peak, which corresponds to the transformation of catechol (1a) to $o$-benzoquinone (2a) and vice versa within a two-electron process. ${ }^{20,22,23}$ Under these conditions, peak current ratio $\left(I_{\mathrm{p}}^{\mathrm{C} 1} / I_{\mathrm{p}}^{\mathrm{A} 1}\right)$ of nearly unity, can be considered as a criterion for the stability of $o$-benzoquinone under the experimental conditions. But, in basic solutions, the peak current ratio $\left(I_{\mathrm{p}}^{\mathrm{Cl}} / I_{\mathrm{p}}^{\mathrm{A} 1}\right)$ is less than unity and decreases with increasing $\mathrm{pH} .{ }^{22}$ This behaviour is related to the coupling of the anionic or dianionic forms of catechol with $o$-benzoquinone (dimerization reaction). ${ }^{22}$ On the other hand, it is shown that indole and its derivatives such as 1-methylindole (3) form dimer or trimer on acid-catalysed conditions. ${ }^{24}$ Consequently in this work, because of the

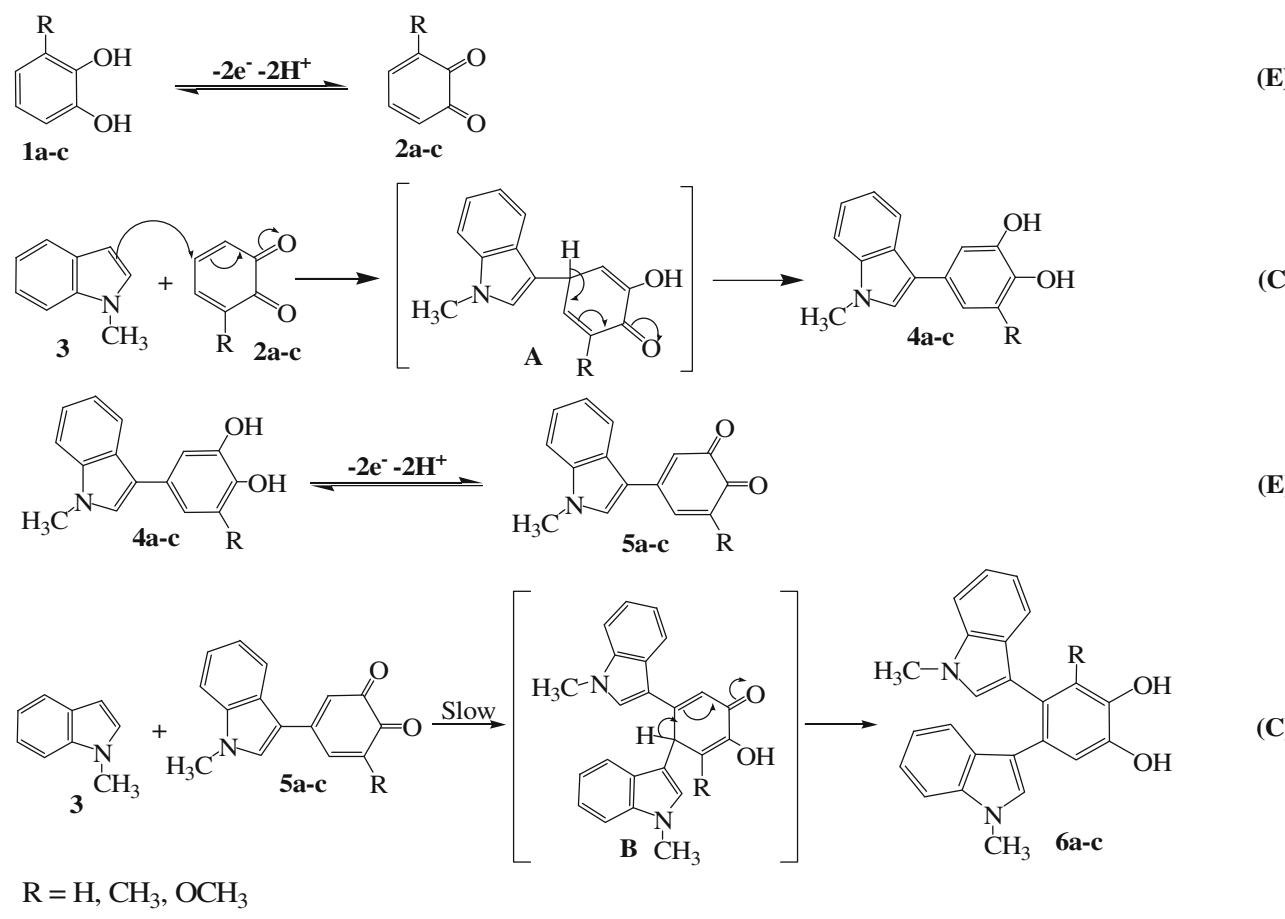

Scheme 1. Electrochemical oxidation mechanism of catechol, 3-methyl catechol and 3-methoxycatechol in the presence of 1-methylindole. 
decrease in the rate of the polymerization of catechol on the one hand and prevention of dimerization of 1-methylindole (3) on the other hand, a solution containing phosphate buffer $(c=0.2 \mathrm{M}, \mathrm{pH}=6.0) /$ acetonitrile $(50: 50 \mathrm{v} / \mathrm{v})$ mixture has been selected as a suitable medium for the electrochemical study and synthesis.

Controlled-potential coulometry was performed in water (containing phosphate buffer, $c=0.2 \mathrm{M}$, $\mathrm{pH}=6.0) /$ acetonitrile $(50: 50 \mathrm{v} / \mathrm{v})$ mixture containing $0.30 \mathrm{mmol}$ of $1 \mathbf{a}$ and $0.60 \mathrm{mmol}$ of 1-methylindole (3) at $0.35 \mathrm{~V}$ versus SCE. The electrolysis was monitored by cyclic voltammetry. It was observed that anodic peak $A_{1}$ decreases proportionally to the advancement of coulometry. All anodic and cathodic peaks disappear when the charge consumption becomes about $4 \mathrm{e}^{-}$per molecule of 1a (figure 3).

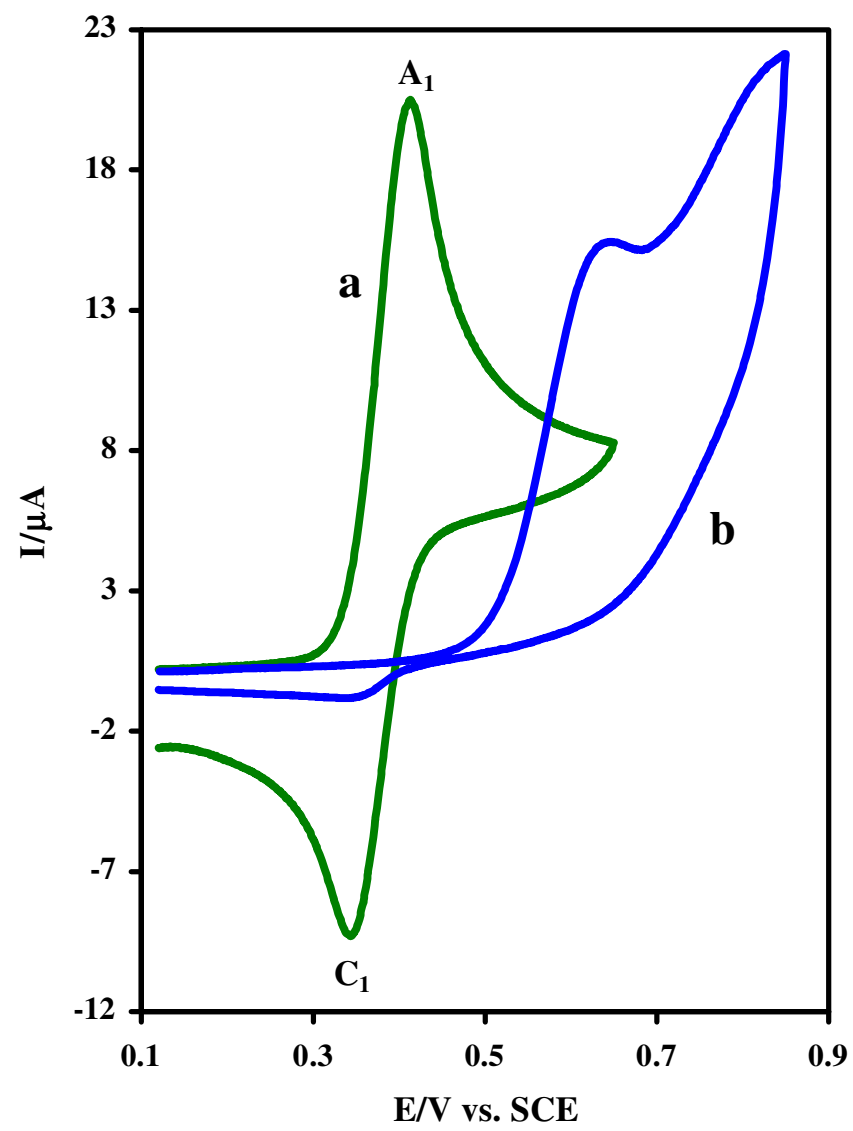

Figure 4. Cyclic voltammograms of (a) $1 \mathrm{mM}$ 2,3dihydroxybenzoic acid (1d), (b) $3 \mathrm{mM}$ of 1-methylindole (3) in water (containing phosphate buffer, $c_{\mathrm{H}_{2} \mathrm{PO}^{-}}=0.188 \mathrm{M}$ and $\left.c_{\mathrm{HPO}^{2-}}=0.012 \mathrm{M}, \mathrm{pH}=6.0\right) /$ acetonitrile $(50: 50 \mathrm{v} / \mathrm{v})$ mixture at glassy carbon electrode. Scan rate: $100 \mathrm{mV} \mathrm{s}^{-1}$; $\mathrm{t}=25 \pm 1^{\circ} \mathrm{C}$
Diagnostic criteria of cyclic voltammetry and controlled potential coulometry accompanied by a molecular mass of 368 of the final product (6a), obtained during macroscale electrolysis, (see Supporting Information), indicates that the reaction mechanism of electrooxidation of catechol (1a) in the presence of 1methylindole (3), in water (phosphate buffer, $c=$ $0.2 \mathrm{M}, \mathrm{pH}=6.0) /$ acetonitrile $(50: 50 \mathrm{v} / \mathrm{v})$ mixture is ECEC (scheme 1). ${ }^{25-30}$

Generation of $o$-benzoquinone $\mathbf{2 a}$ is followed by a Michael addition of $\mathbf{3}$ to the benzoquinone $\mathbf{2 a}$, producing the compound $4 \mathbf{a}$. In applied potential $(0.35 \mathrm{~V}$ vs. $\mathrm{SCE}$ ), $\mathbf{4 a}$ is converted to $o$-benzoquinone $\mathbf{5 a}$. In final stage, the 'slow' next Michael addition reaction, converts $5 \mathbf{a}$ to catechol derivative $\mathbf{6 a}$ as a final product. The oxidation of $\mathbf{6 a}$ was circumvented during the preparative reaction because of the insolubility of it in water

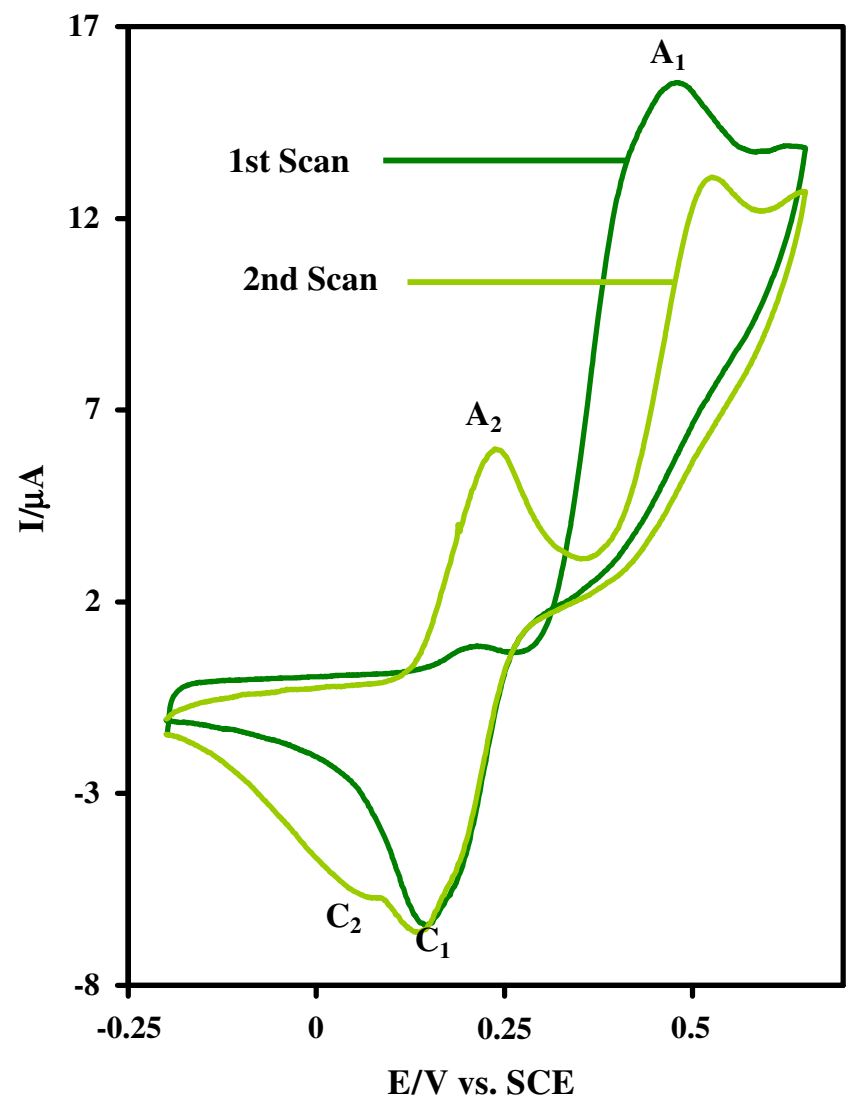

Figure 5. First and second cycle of cyclic voltammograms of $1 \mathrm{mM}$ 2,3-dihydroxybenzoic acid (1d) in the presence of $1 \mathrm{mM} 1$-methylindole (3) at glassy carbon electrode, in water (containing phosphate buffer, $c_{\mathrm{H} 2 \mathrm{PO} 4^{-}}=0.188 \mathrm{M}$ and $\left.c_{\mathrm{HPO} 4^{2-}}=0.012 \mathrm{M}, \mathrm{pH}=6.0\right) /$ acetonitrile $(50: 50 \mathrm{v} / \mathrm{v})$ mixture. Scan rate: $50 \mathrm{mV} \mathrm{s}^{-1} ; \mathrm{t}=25 \pm 1^{\circ} \mathrm{C}$. 
(phosphate buffer, $c=0.2 \mathrm{M}, \mathrm{pH}=6.0$ )/acetonitrile $(50: 50 \mathrm{v} / \mathrm{v})$ mixture.

The same results are obtained in electrochemical oxidation of 3-methylcatechol (1b) and 3-methoxycatechol (1c).

\subsection{Electrochemical oxidation of 2,3-dihydroxybenzoic acid in the presence of 1-methylindole}

The cyclic voltammogram of 2,3-dihydroxybenzoic acid (1d) in the absence of 1-methylindole (3) (figure 4, curve a) shows one anodic peak $\left(\mathrm{A}_{1}\right)$ at $0.42 \mathrm{~V}$ and the corresponding cathodic peak $\left(\mathrm{C}_{1}\right)$ at $0.33 \mathrm{~V}$, which corresponds to the transformation of 2,3-dihydroxybenzoic acid (1d) into the related $o$-benzoquinone (5,6dioxocyclohexa-1,3-dienecarboxylic acid, 2d) and vice versa within a two-electron process. ${ }^{23}$ As can be seen, in time scale of our experiments, the peak current ratio $\left(I_{\mathrm{p}}^{\mathrm{C} 1} / I_{\mathrm{p}}^{\mathrm{A} 1}\right)$ which can be considered as a criterion for instability of $o$-benzoquinone $\mathbf{2 d}$ is less than unity. The instability of $o$-benzoquinone $\mathbf{2 d}$ can be due to the participation of it in hydroxylation or dimerization reactions. ${ }^{31-35}$ In this figure, curve $\mathrm{b}$ is the voltammogram of $\mathbf{3}$.

The oxidation of 2,3-dihydroxybenzoic acid (1d) in the presence of 1-methylindole (3) was studied in some detail (figure 5). Under these conditions, the anodic peak current $\mathrm{A}_{1}$ increases and the cathodic counterpart of it (peak $\mathrm{C}_{1}$ ) decreases. In addition, in second cycle, new anodic and cathodic peaks $\left(\mathrm{A}_{2}\right.$ and $\left.\mathrm{C}_{2}\right)$ appear at less positive potential in comparison with peaks $\mathrm{A}_{1}$ and $\mathrm{C}_{1}$.

For more data, the influence of the potential sweep rate on the shape of cyclic voltammograms of a solution of $\mathbf{1 d}$ in the presence of $\mathbf{3}$ has been studied. The results show that proportional to the increasing of the potential sweep rate, the peak current ratio $\left(I_{\mathrm{p}}^{\mathrm{C} 1} / I_{\mathrm{p}}^{\mathrm{A} 1}\right)$ increases. It reaches to nearly unity in higher sweep rates. Also, disappearance of peak $\mathrm{A}_{2}$ in higher sweep rates is another aspect of increasing of sweep rate. This is indicative of departure from intermediate and arrival to diffusion region with increasing sweep rate. ${ }^{21}$ This peak $\left(\mathrm{A}_{2}\right)$ can be related to the oxidation of intermediate 6d (see scheme 2). A comparable condition is observed when the $\mathbf{3}$ to $\mathbf{1 d}$ concentration ratio is decreased.

Controlled-potential coulometry was performed in water (phosphate buffer, $c=0.2 \mathrm{M}, \mathrm{pH}=6.0$ )/acetonitrile $(50: 50 \mathrm{v} / \mathrm{v})$ mixture containing $0.25 \mathrm{mmol}$ of 2,3-dihydroxybenzoic acid (1d) and $0.50 \mathrm{mmol}$ of $\mathbf{3}$ at potential of peak $A_{1}$. Cyclic voltammetric analysis carried out during the electrolysis shows the progressive formation of anodic peak $\mathrm{A}_{2}$ and cathodic peak $C_{2}$, parallel to the disappearance of the peak $A_{1}$ (figure 6 , curves I). This peak $\left(\mathrm{A}_{1}\right)$ disappears when the charge consumption becomes about $6 \mathrm{e}^{-}$per molecule of $\mathbf{1 d}$.

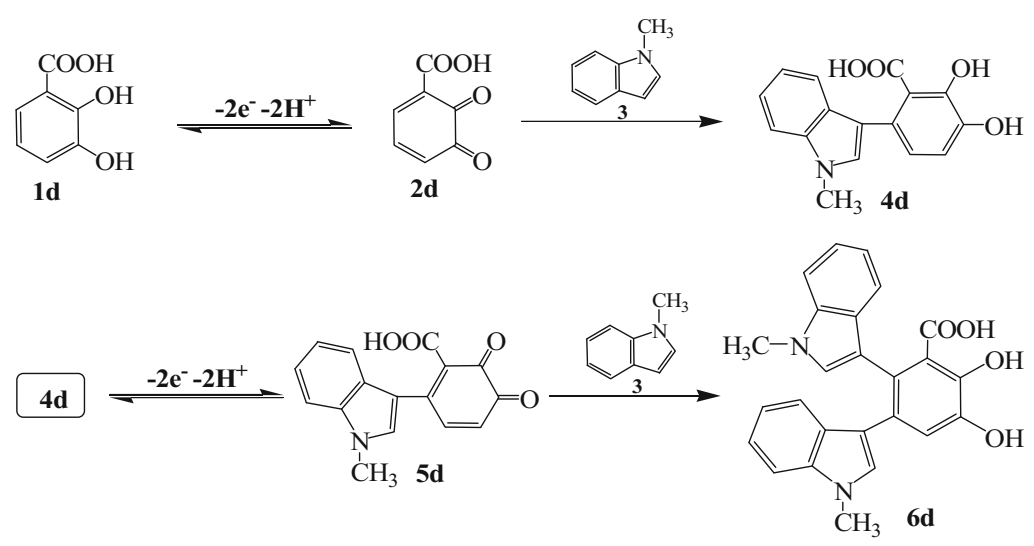

(EC)

(EC)

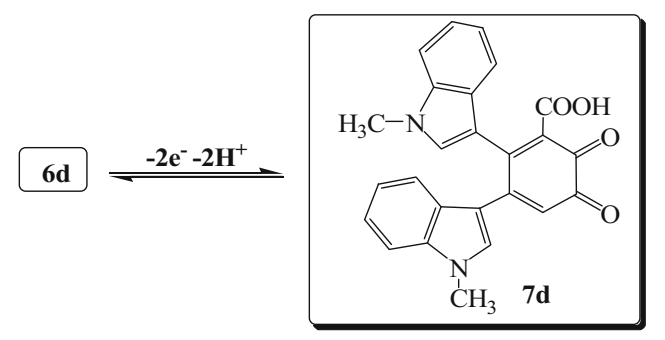

(E)

Scheme 2. Electrochemical oxidation mechanism of 2,3-dihydroxybenzoic acid in the presence of 1-methylindole. 
Another important difference between voltammograms in figure 6 , is related to the amounts of currents at starting potential $(-0.25 \mathrm{~V}$ versus SCE) (see, figure 6, curves II). The results show that the amount of current for curve a at starting potential is nearly zero, but curves $\mathrm{b}-\mathrm{d}$ show cathodic currents at starting potential. These cathodic currents increase with progress of coulometry. These currents are related to reduction of produced 7d.
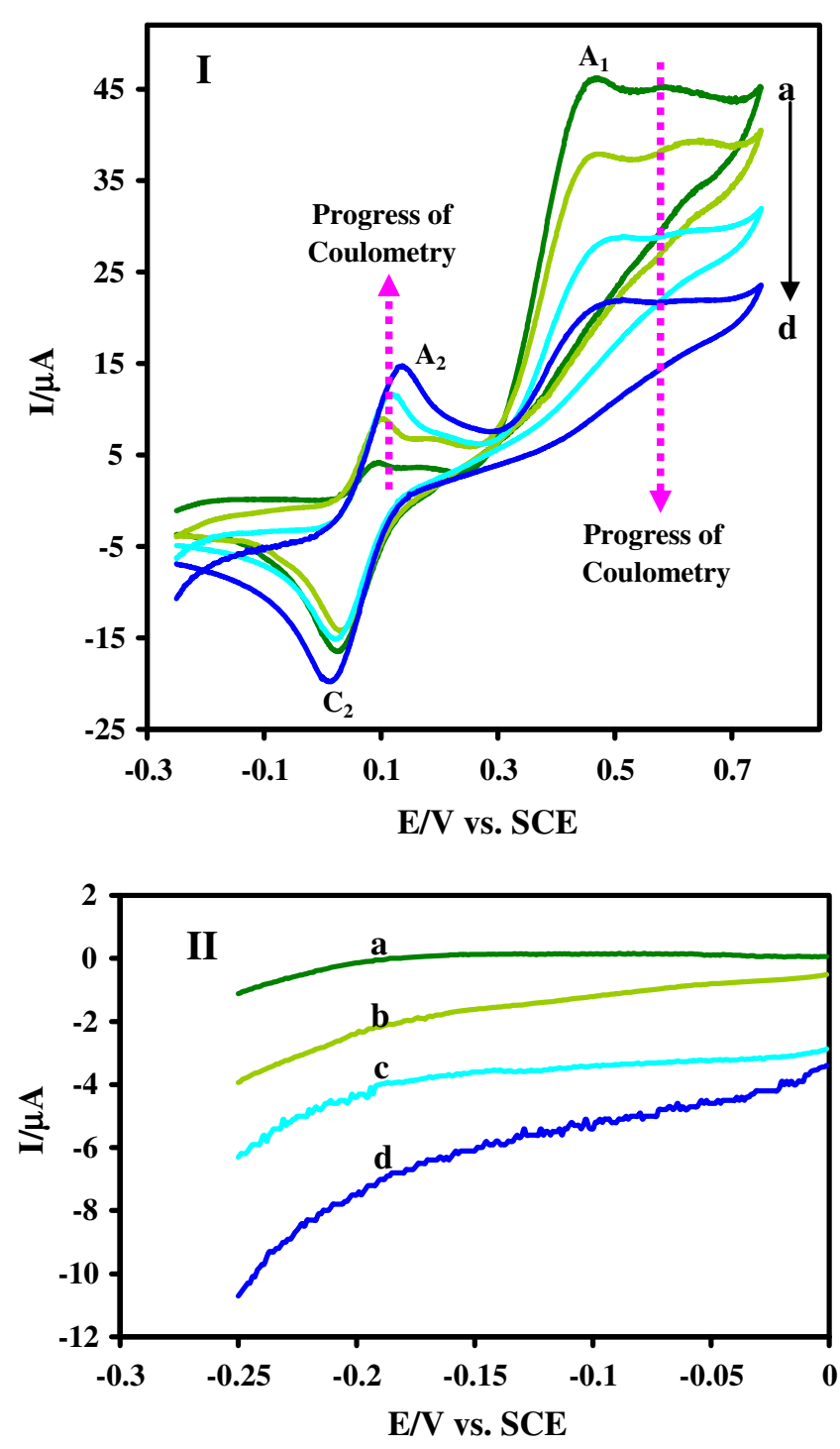

Figure 6. Cyclic voltammograms of $0.25 \mathrm{mmol} 2,3-$ dihydroxybenzoic acid (1d) in the presence of $0.50 \mathrm{mmol}$ 1-methylindole (3), at glassy carbon electrode in water (phosphate buffer, $c=0.2 \mathrm{M}, \mathrm{pH}=6.0$ )/acetonitrile $(50: 50 \mathrm{v} / \mathrm{v})$ mixture during controlled-potential coulometry at $0.40 \mathrm{~V}$ vs. SCE, after the consumption of (a) 0 , (b) 30 , (c) 60 and (d) 90 C. Scan rate: $100 \mathrm{mV} \mathrm{s}^{-1}$; t $=25 \pm 1^{\circ} \mathrm{C}$. Curves II are as same as I, from -0.25 to $0.00 \mathrm{~V}$ vs. SCE.
These voltammetric and coulometric data is accompanied by a molecular mass of 410 of the final product (7d), obtained during macroscale electrolysis, (see Supporting Information) lead us to propose the following mechanism (ECECE) for electrochemical oxidation of 2,3-dihydroxybenzoic acid (1d) in the presence of $\mathbf{3}$ (scheme 2). ${ }^{36}$

According to our results, it seems that the Michael addition reaction of the 1-methylindole (3) to $O$ benzoquinone $\mathbf{2 a}$ is faster than other side reactions and leads to intermediate $\mathbf{4 d}$. In applied potential $\mathbf{4 d}$ is converted to $o$-benzoquinone $5 \mathbf{d}$. In the next step, $o$ benzoquinone 5d, via another intermolecular Michael reaction, is converted to intermediate $\mathbf{6 d}$. Further oxidation converts intermediate $\mathbf{6 d}$ into the final product 7d.

Accordingly, the anodic peaks $\mathrm{A}_{1}$ and $\mathrm{A}_{2}$ pertain to the oxidation of 2,3-dihydroxybenzoic acid (1d) and dihydroxybenzoic acid $\mathbf{6 d}$ to the $o$-benzoquinone $\mathbf{2 d}$ and 7d, respectively. Obviously, the cathodic peaks $C_{1}$ and $\mathrm{C}_{2}$ correspond to the reduction of $o$-benzoquinones $\mathbf{2 d}$ and $\mathbf{7 d}$, respectively.

\subsection{Electrochemical oxidation of 3,4-dihydroxybenzoic acid in the presence of 1-methylindole}

Such as 2,3-dihydroxybenzoic acid (1d), the same voltammetric data have been obtained in the case of 3,4-dihydroxybenzoic acid (1e). But, contrary to the previous case, the mass spectrum of final product obtained from electrochemical oxidation of 3,4dihydroxybenzoic acid (1e) in the presence of 1methylindole (3) shows mass $=426 \mathrm{~g} / \mathrm{mol}$. Diagnostic criteria of voltammetry accompanied by the molecular mass of the final product, obtained during macroscale electrolysis, (see Supporting Information), indicates that the reaction mechanism of electrooxidation of $\mathbf{1 e}$ in the presence of 1-methylindole (3) in our electrolysis condition, is ECECECE (scheme 3). ${ }^{37}$

According to scheme 3, it seems that the Michael addition reaction of $\mathbf{3}$ to $o$-benzoquinone $\mathbf{2 e}$ is faster than other side reactions and leads to intermediate 4e. The next oxidation process converts $4 \mathbf{e}$ to $o$ benzoquinone 5e. In the next step, $o$-benzoquinone $\mathbf{5 e}$, via a Michael reaction, is converted to intermediate 6e. Another oxidation process transforms intermediate 6e to $o$-benzoquinone 7e. Michael addition reaction of water to $o$-benzoquinone $\mathbf{7 e}$, converts $\mathbf{7 e}$ to intermediate $\mathbf{8 e}$ and further oxidation converts intermediate $8 \mathbf{e}$ into the final product $9 \mathbf{e}$. 


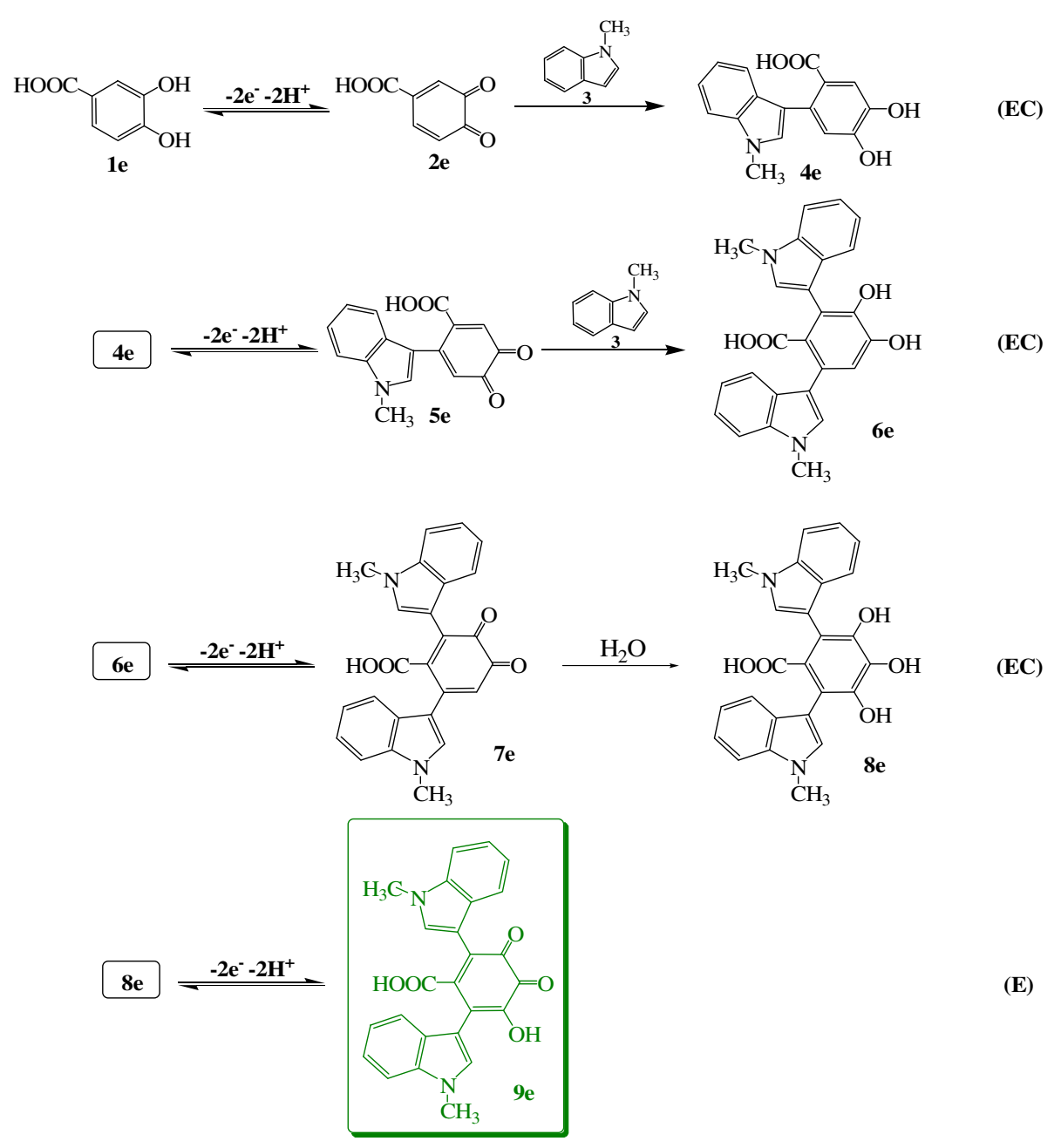

Scheme 3. Electrochemical oxidation mechanism of 3,4-dihydroxybenzoic acid in the presence of 1-methylindole.

\section{Conclusion}

The reaction scheme for oxidation of catechol (1a), 3-methylcatechol (1b) and 3-methoxycatechol (1c) in the presence of 1-methylindole (3), in water (phosphate buffer, $c_{\mathrm{H}_{2} \mathrm{PO}^{-}}=0.188 \mathrm{M}$ and $c_{\mathrm{HPO}^{2-}}=0.012 \mathrm{M}$, $\mathrm{pH}=6.0)$ /acetonitrile $(50: 50 \mathrm{v} / \mathrm{v})$ mixture is presented (scheme 1). In the case of these catechols, the over-oxidation of compounds $\mathbf{6 a}-\mathbf{c}$ were circumvented during the preparative reaction because of the insolubility of the final products. The reaction scheme for oxidation of 2,3-dihydroxybenzoic acid (1d) in the same conditions is presented (scheme 2). In this case, because of the presence of carboxyl group in structure of intermediate $\mathbf{6 d}$ and solubility of it in electrolysis medium, the final product $\mathbf{7 d}$ was obtained after over-oxidation of $\mathbf{6 d}$. The reaction scheme for oxidation of 3,4-dihydroxybenzoic acid (1e) is presented (scheme 3). The oxidation, Michael addition reaction of water and over-oxidation convert intermediate $6 \mathbf{e}$ to product $9 \mathbf{e}$.

\section{Supporting information}

Mass spectra of $6 \mathbf{a}, 7 \mathbf{d}$ and $9 \mathbf{e}$ are provided as supplementary material (figures S1-S3). See www.ias. ac.in/chemsci for supporting information.

\section{Acknowledgements}

The authors acknowledge the support received from the Bu-Ali Sina University Research Council and Center of Excellence in Development of Chemical Methods (CEDCM). 


\section{References}

1. Süzen S 2007 Antioxidant activities of synthetic indole derivatives and possible activity mechanisms (Heidelberg, Berlin: Springer)

2. Aggarwal B B and Ichikawa H 2005 Cell Cycle 41201

3. AMICBASE-EssOil 1999-2002 Database on Natural Antimicrobials Review Science, Germany

4. Pauli A 2002 Third World Congress on Alleopathy Tsukuba, Japan, August 26-30

5. Nematollahi D, Dehdashtian S and Niazi A $2008 \mathrm{~J}$. Electroanal. Chem. 61679

6. Arai K and Yamamoto Y 1990 Chem. Pharm. Bull. 38 2929

7. Kaji A, Saito R, Nomura M, Miyamoto K and Kiriyama N 1998 Biol. Pharm. Bull. 21945

8. Arai K, Shimizu S, Taguchi Y and Yamamoto Y 1981 Chem. Pharm. Bull. 29991

9. Shimizu S, Yamamoto Y and Koshimura S 1982 Chem. Pharm. Bull. 301896

10. Kaji A, Iwata T, Kiriyama N, Wakusaw S and Miyamoto K 1994 Chem. Pharm. Bull. 421682

11. Nematollahi D and Dehdashtian S 2008 Tetrahedron Lett. 49645

12. Sohn J, Kiburz B, Li Z, Deng L, Safi A, Pirrung M C and Rudolph J 2003 J. Med. Chem. 462580

13. Yadav J S, Reddy B V S and Swamy T 2003 Tetrahedron Lett. 449121

14. Mohlau R and Redlich R 1911 Ber. Dtsch. Chem. Ges. 443605

15. Bu'Lock J D and Harley-Mason J 1951 J. Chem. Soc. 703

16. Maiti A K and Bhattacharya P 1997 J. Chem. Res. (S) 424

17. Pirrung M C, Park K and Li Z 2001 Org. Lett. 3365

18. Pirrung M C, Deng L, Li Z and Park K 2002 J. Org. Chem. 678374

19. Pirrung M C, Fujita K and Park K 2005 J. Org. Chem. 702537
20. Nematollahi D, Rafiee M and Fotouhi L 2009 J. Iran. Chem. Soc. 6448

21. Bard A J and Faulkner L R 2001 Electrochemical methods, 2nd Ed. (New York: Wiley) p 496

22. Nematollahi D and Rafiee M 2004 J. Electroanal. Chem. 56631

23. Nematollahi D, Taherpour A, Jameh-Bozorghi S, Mansouri A and Dadpou B 2010 Int. J. Electrochem. Sci. 5867

24. Smith G F 1963 Advances in Heterocyclic Chemistry (ed) A R Katritzky (New York: Academic Press INC) Vol. 89, pp. 300

25. Nematollahi D, Habibi D, Rahmati $M$ and Rafiee $M$ 2004 J. Org. Chem. 692637

26. S.Hosseiny Davarani S, Nematollahi D. Mashkouri Najafi N, Masoumi L and Ramyar S 2006 J. Org. Chem. 712139

27. Nematollahi D, Amani A and Tammari E 2007 J. Org. Chem. 723646

28. Nematollahi D and Goodarzi H 2002 J. Org. Chem. 67 5036

29. Nematollahi D and Rafiee M 2005 Green Chem. 7 638

30. Raoof J B, Ojani R, Nematollahi D and Kiani A 2009 Int. J. Electrochem. Sci. 4810

31. Nematollahi D, Rafiee M and Samadi-Maybodi A 2004 Electrochim. Acta 492495

32. Ryan M D, Yueh A and Wen-Yu C 1980 J. Electrochem. Soc. 1271489

33. Papouchado L, Petrie G and Adams R N 1972 J. Electroanal. Chem. $\mathbf{3 8} 389$

34. Papouchado L, Petrie G, Sharp J H and Adams R N 1968 J. Am. Chem. Soc. 905620

35. Young T E, Griswold J R and Hulbert M H 1974 J. Org. Chem. 391980

36. Habibi D, Nematollahi D and Azimi S 2008 Tetrahedron Lett. 495043

37. Nematollahi D, Tammari E and Karbasi H 2007 Int. J. Electrochem. Sci. 2986 